\title{
Julia Twigg (2013). Fashion and Age. Dress, the Body and Later Life. London: Bloomsbury, 174 pp. ISBN 9781874886965 (paperback)
}

\author{
Reviewed by Maricel Oró Piqueras*
}

In Fashion and Age. Dress, the Body and Later Life, Julia Twigg explores how fashion and age "sit uncomfortably together" (p. 1). Despite the exponential ageing of Western population, fashion is primarily related to youthful beauty as opposed to the "greyness" associated with age. Twigg notes that little research has been pursued in fashion studies beyond the age of 40. Still, clothes provide rich information in relation to social position, gender and age and they are key in the social and individual presentation of ourselves. In her study, Julia Twigg looks at what she calls "the tradition of age ordering in dress" (p. 3) in which dress patterns are shaped and associated to both the changes the body experiments with age and also the cultural conceptions of what is acceptable and unacceptable in every stage of the lifecourse. When looking at the question of gender closely, Twigg argues that focussing on dress can actually have a positive side, in which women appreciate the aesthetic pleasure of dress. However, dress can also be related to objectification and, thus, it becomes the best companion of invisibility and marginalisation of women in old age. Although Twigg acknowledges that men also suffer from restrictive socially accepted dress

* Maricel Oró Piqueras, Department of English and Linguistics, University of Lleida, Lleida, Spain 
International Journal of Ageing and Later Life

styles as they age, she argues that normative femininity is equated to an image of youthfulness which leaves those women who do not comply with it in a kind of limbo that she describes as a "cultural exile from femininity" (p. 5).

Fashion and Age. Dress, the Body and Later Life is especially interesting because of the different points of view and perspectives which Twigg explores in relation to dress, fashion and ageing. The book is divided into eight chapters among which an introduction and conclusion are included. Chapters 2-3 focus on the relationship between clothing and fashion as "age ordering" and explore the meanings attached to an ageing and old body within a cultural framework. Thereafter, chapters 4-7 examine the interrelationship between the previously mentioned items through the voices and life narrations of older women, the discourses of the media through interviewing fashion editors and journalists as well as the voice of the fashion industry with the testimony of design directors for major clothing retailers. Including the first-person narrations, testimonies and answers to specific questions of these consumers, producers and publicists regarding fashion and old age give a three-dimensional perspective and a clearly added value to Twigg's study. Moreover, the interviews and analysis support Twigg's initial thesis. According to her, whereas contemporary generations of older people, especially women, as well as media and the fashion industry are engaged in presenting "new ways of being an older person" (p. 5), this new concept of ageing is never completely distanced from normative femininity. In this respect, cultural conceptions of both old age and fashion are still prevalent.

Julia Twigg obtains the voices of older women from an empirical study based on interviews with respondents aged 55 and over, from different social backgrounds and employment circumstances. In chapters 5-6, Twigg is especially interested in exploring older women's choices of dress and their feelings about these choices in relation to age ordering and social expectations, as well as in relation to the impact and role of bodily changes. Twigg argues that, in general, respondents adopted a "cautious, conservative style" (p. 52) both when attending the interviews but also when choosing their clothes. A common idea that Twigg registered in the women she interviewed was the need to be careful, which brings the 
author to the conclusion that cultural ageing "comes upon the individual gradually, operating throughout the life course" (p. 53). Despite the fact that most of the respondents in her study did not feel they had changed that much since their younger years, they adopted dress styles and colours which they believed appropriate for their ages. Appropriateness was either seen as moving away from fashion and, thus, for some of the respondents it meant giving away a pleasurable part of their identity; or, in order to stay in fashion, strict discipline had to be imposed over their bodies. In this respect, Twigg's studies stays in line with Kathleen Woodward's (1999) and Margaret Cruickshank's (2002) earlier studies in which the signs of ageing in women could only be translated in either invisibility or masquerade; thus, leaving very limiting and limited options for women in old age. However, Twigg also senses a shift in women's attitudes in how they intend to present themselves to the world. Without forgetting appropriateness, Twigg's respondents also attached the fact of keeping a good appearance with signalling to the outside world their status as respectable older women. In this sense, the author of the study argues that older women are buying more clothes than in the past, they are wearing a wider colour palette and they are sticking to garments which they had worn since their youth such as jeans and tops, which opposed choices their mothers and grandmothers had made in old age.

Through the analysis of four magazines with fashion as a prominent ingredient and aimed at different sectors of the market -Woman \& Home, SAGA, Yours, Vogue - the analysis of five British retail chains - Marks \& Spencer, George at Asda, Viyella, Jaeger and The Edinburgh Woollen Mill - and interviewing representatives of both sectors, Twigg concludes that, despite being aware of the need of trying to appeal to a growing target of the population over 50, the editorial lines as well as design and marketing strategies of these enterprises are still based on essentially ageist beliefs.

All in all, Julia Twigg's study is a valuable source of data and worth considering analysis of the intersections between fashion and clothes, the body and identity related to the changes the body experiences with the passing of time and the still limiting and limited cultural and social assumptions attached to old age, particularly in women. 
International Journal of Ageing and Later Life

\section{References}

Cruickshank, M. (2002). Learning to be Old. Gender, Culture and Aging. Margaret Cruikshank. Lanham, MD: Rowman and Littlefield.

Woodward, K. (1999). Figuring Age. Women, Bodies, Generations.

K. Woodward (ed.), Bloomington, IL: Indiana University Press. 